\title{
Pain and anxiety control in dentistry - the foundation of successful practice, but the cinderella of dental pre- registration education
}

\author{
Nigel D Robb* \\ Reader/Honorary Consultant in Restorative Dentistry, School of Oral and Dental Sciences, University of Bristol, Lower Maudlin Street, Bristol, BS1 2LY, UK
}

The control of patients' pain and anxiety has been a fundamental part of the practice of dentistry since Horace Wells underwent dental treatment using nitrous oxide anaesthesia in 1844, and subsequently used it on his own patients prior to an ill-fated demonstration in Massachusetts General Hospital in 1845 [1]. The use of nitrous oxide was the first of a number of major milestones in this area. These included the use of ether by William TG Morton in 1846 [2], and the first administration of local anaesthesia for dentistry by William Halsted in 1844 [3]. The development of inhalation sedation for dentistry, as opposed to general anaesthesia, was popularised by Harry Langha who first described the technique in the 1940s before running the first postgraduate sedation course in 1949 [4]. Techniques of intravenous sedation followed with the work of Jorgensen in 1945 and then Drummond-Jackson the founder of the Society for the Advancement of Anaesthesia in Dentistry in 1957 [5].

It is a sad indictment of the dental profession that in the $21^{\text {st }}$ century anxiety and fear of dental care remains one of the most common phobias in the western world despite the advancement in the armamentarium available to the profession to control pain and anxiety. These have included: the development of new local anaesthetic solutions (lidocaine, prilocaine, mepivicaine and articaine); the introduction of topical anaesthetics; the development of new computer controlled delivery devices (the so called CCLAD systems); and the introduction of benzodiazepines as safe and effective sedatives to control dental anxiety. All are readily available to the profession as a whole, but in 2009, 12\% of the population in the Adult Dental Health Survey in England and Wales had a Modified Dental Anxiety Score (MDAS) of more than 19, indicative of severe dental anxiety [6].

Perhaps the key lies in the way our preregistration students are educated (or not) about pain and anxiety control.

Leitch and Girdler published a survey of the teaching of sedation in UK dental schools in 2000 [7]. At that point, although all but 2 of the schools which responded provided didactic teaching, the mean number of lectures was 4.2 and the mean number of seminars only 1.8. Only 2 schools provided hands-on clinical experience of treating patients under intravenous sedation although 12 provided Inhalation sedation experience.

Jagsi repeated this study in 2012 [8]. The response rate was $9 / 12$ for questionnaires completed by staff which showed that there was a mean of 7 lectures and 3 tutorials covering sedation. The range was from 2 lectures and 1 tutorial to 11 lectures and 3 tutorials. In 8 of the 9 schools the students performed Inhalation Sedation on an average of
3 occasions with a range or 1 to 6 administrations. Students performed intravenous sedation in all 9 of the schools which responded to the survey. The average number of administrations was 4 with a range from 2 to 6 . It can thus be seen that in the UK although the experience of the students increased in the 12 years between the reports, the experience is minimal.

The adequacy of the provision can be judged against the standard of what would be needed to achieve competence for independent practice. The Dental Sedation Teachers Group [9] published guidance on the amount of supervised clinical practice that would be recommended for dentists wishing to achieve competence. The recommendations were for 10 cases of Inhalation Sedation and 20 cases of IV sedation as the experience that most of the profession required. It can thus be seen that in terms of the average UK experience students were gaining a third of that required for Inhalation sedation and a fifth for Intravenous Sedation. The aim of pre-registration is not to produce the competent practitioner, but to produce a "safe beginner" ready to continue a lifetime of learning.

In 2016, Oliver, et al. published the results of a survey of the teaching of local anaesthesia in UK dental schools [10]. The results showed that whilst there was a range in the amount of teaching, the largest number of hours was devoted to self-directed learning. The mean number of hours devoted to lectures and tutorials was 8 and 3 respectively. It is difficult to know how precise the individuals were when counting the hours, as teaching in physiology relating to the generation and propagation of nerve impulses might be included along with teaching that takes place as part of courses in anatomy and pharmacology. It may be that the reason that the range in hours devoted to teaching ranged from 2 to 201 relates to the perceptions of those completing the survey. Even at best the teaching and learning experience of local anaesthesia is 40 hours per year averaged over 5 years. To put this in context, in the undergraduate course in Bristol the third year students have 5 hours of lectures and 103 -hour practical sessions on Orthodontic Skills. In the $4^{\text {th }}$ year of the course the students have a course entitled Oral Disease where there are 39 lectures covering Oral Medicine and Pathology, Radiology, Special Care Dentistry, Maxillofacial Surgery and Oral Microbiology.

Correspondence to: Nigel D Robb, TD, PhD, BDS, FDSRCSEd, FDS(Rest Dent), FDSRCPS, FHEA, Reader/Honorary Consultant in Restorative Dentistry, School of Oral and Dental Sciences, University of Bristol, Lower Maudlin Street, Bristol, BS1 2LY, UK, E-mail: nigel.robb@bristol.ac.uk

Received: January 09 2017; Accepted: January 23, 2017; Published: January 25 , 2017 
The course organiser indicates that for each lecture, the students are expected to undertake pre-lecture reading for approximately 1-2 hours and then 1-2 hours of post lecture study.

The examples chosen are taken from personal experience, but other equally valid examples could be found in any other dental school in the world.

Whilst not wishing to denigrate the teaching of other areas in dentistry, or indeed any particular dental school, when one looks at the practicing life of the majority of dental graduates, pain and anxiety control is such an important part of the practice of dentistry, that it is surely under-represented in the current dental curricula.

In 2009 the Association for Dental Education in Europe published a document entitled "Profile and competences for the graduating European dentist - update 2009" [11]. In that document there are a number of recommendations outlining 17 major competencies that dental schools are expected to follow. There are also supporting competencies that "may vary in detail between schools". The introduction of this document includes the following text "One of the objectives continues to be 'to tune' curricula in terms of structures, programmes and actual teaching to make them more comparable. Thus, it will be easier for staff and students to move around in an integrated Europe and obtain reliable information about the role of a dental qualification. A single European social and economic area goes hand in hand with a single European Higher Education Area".

The particular areas of note are under Domain 6 "therapy: establishing and maintaining oral health". In supporting competency 6.24, it states that on graduation the dentist must be competent at: "Administering infiltration and block local anaesthesia in the oral cavity for restorative and surgical procedures or other treatment, as needed/required, for oro-facial pain management, including management of potential complications of local anaesthesia." In supporting competency 6.70 , it states that the graduating dentist must have knowledge of: "Inhalation, intravenous and other conscious sedation techniques for dental procedures in adults, children, disabled patients and those with systemic diseases".

The definitions of the levels of competence to be attained are defined as follows:

Be competent at: a dentist should on graduation demonstrate a sound theoretical knowledge and understanding of the subject together with an adequate clinical experience to be able to resolve clinical problems encountered independently or without assistance.

Have knowledge of: a dentist should on graduation demonstrate a sound theoretical knowledge and understanding of the subject, but may have only limited clinical/practical experience.

Be familiar with: a dentist should on graduation demonstrate a basic understanding of the subject but need not have clinical experience or be expected to carry out procedures independently.

Thus all graduates are expected to have some clinical experience of inhalation and intravenous sedation techniques including the administration to patients. What level of clinical experience equates to "have knowledge of" as defined by ADEE? This has not been defined. Is the experience of the dental pre-registration training in the UK sufficient? Many would argue that it is not.

So what of the experience elsewhere in Europe. In 2006, the author presented the results of a survey of teaching of pain and anxiety control in countries with specialist societies affiliated to the European Federation for the Advancement of Anaesthesia in Dentistry to the Triennial Meeting of the International Federation of Dental Anaesthesiology Societies [12]. There is no consistency of training or practice across Europe. In the UK the majority of dental schools included some training in both intravenous and inhalation sedation techniques. In the UK and Germany it is common for dental professionals to practice Intravenous Sedation and there are regular courses, which in Germany are targeted predominantly at Oral Surgeons.

In Spain, France and Italy a common response to questions regarding the possibility of dentists administering intravenous sedation is that it is not allowed. Several Italian anaesthetists have told me that it is illegal for dentists to administer intravenous drugs. Despite frequent requests, a copy of the legislation has still not been sent to me.

The current situation is completely unsatisfactory in that educational recommendations from 8 years ago are still largely ignored by the dental schools. The knowledge levels of graduating and practising dentists in relation to controlling their patients' fears and anxieties are such that patients continue to find dental treatment painful and distressing, when there are tools available to control pain and anxiety effectively. The competence and training of newly qualified dentists across Europe still is extremely variable, despite which there is freedom of movement and the expectation of being able to practice in any country in the EU. The differing expectations of patients and dentists in terms of how pain and anxiety should be managed can put pressure on dentists to deliver care beyond their competency, and can result in dissatisfaction from patients unable to access care that they have become accustomed to receiving.

The impact of the UK's vote to leave the EU on the activities of ADEE remains to be seen. The $21^{\text {st }}$ century should be the time when the world becomes a smaller place and there is more consistency in the practice and training of the dental profession utilising a patient centred, evidence based approach. What is more patient centred than effective pain and anxiety control.

\section{References}

1. Langha $\mathrm{H}$ (1968) Relative analgesia in dental practice. Inhalation analgesia with nitrous oxide. Philadelphia: WB Saunders pp 8-9.

2. Langha $H$ (1968) Relative analgesia in dental practice. Inhalation analgesia with nitrous oxide. Philadelphia: WB Saunders p 11.

3. Mecchan JG, Robb ND, Seymour RA (1998) Pain and anxiety control for the conscious dental patient. Oxford: Oxford University Press. P 30

4. Malamed SF(1995)Sedation. A guide to patient management. $3^{\text {rd }}$ Edition. Mosby: St Louis $\mathrm{p} 194$.

5. Mecchan JG, Robb ND, Seymour RA (1998) Pain and anxiety control for the conscious dental patient. oxford: Oxford University Press pp 301-302.

6. Adult dental health survey 2009 - Summary report and thematic series [NS].Available at:http://content.digital.nhs.uk/pubs/dentalsurveyfullreport09 [Accessed 1 January 2017].

7. Leitch JA, Girdler NM (2000)Conscious sedation: A survey of the teaching of conscious sedation in dental schools of the United Kingdom and Ireland. Brit Dent J188: 211-216. [Crossref]

8. Jagsi, S. (2012). The incorporation of conscious sedation as a mandatory core subject in the undergraduate dental curriculum in the United Kingdom.Final year elective report, University of Bristol.

9. Dental sedation teachers group (2000). The competent graduate. Available at: http:// www.dstg.co.uk/sedation-in-dentistry-the-competent-graduate/[Accessed 1 December 2016].

10. Oliver G, David A, Bell C, Robb N (2016)An investigation into dental local anaesthesia teaching in United Kingdom dental schools. SAAD Digest32: 7-13.[Crossref] 
Robb ND (2017) Pain and anxiety control in dentistry - the foundation of successful practice, but the cinderella of dental pre-registration education

11. Cowpe J, Plasschaert A,HarzerW, Vinkka-Puhakka H, Walmsley AD (2009)Profile and competences for the graduating European dentist - update 2009.Europ J Dent Educ14: 193-202.[Crossref]
12. Robb ND (2006) The training of European Dentists to give sedation. Presentation to IFDAS Triennial Meeting, Yokohama.

Copyright: (C2017 Robb ND. This is an open-access article distributed under the terms of the Creative Commons Attribution License, which permits unrestricted use, distribution, and reproduction in any medium, provided the original author and source are credited. 